\title{
Association between prediagnostic glucose, triglycerides, cholesterol and meningioma, and reverse causality
}

\author{
Brittany M Bernardo ${ }^{1,6}$, Robert C Orellana ${ }^{1,6}$, Yiska Lowenberg Weisband ${ }^{1,6}$, Niklas Hammar ${ }^{2,3}$, \\ Goran Walldius ${ }^{4}$, Hakan Malmstrom ${ }^{3}$, Anders Ahlbom ${ }^{3}$, Maria Feychting ${ }^{3}$ and Judith Schwartzbaum ${ }^{\star, 1,5}$ \\ ${ }^{1}$ Division of Epidemiology, College of Public Health, Ohio State University, Columbus, OH 43210, USA; ${ }^{2}$ AstraZenecaR\&D, \\ Mölndal 43150, Sweden; ${ }^{3}$ Unit of Epidemiology, Institute of Environmental Medicine, Karolinska Institutet, SE-171 77 Stockholm, \\ Sweden; ${ }^{4}$ Unit of Cardiovascular Epidemiology, Institute of Environmental Medicine, Karolinska Institutet, SE-171 77 Stockholm, \\ Sweden and ${ }^{5}$ Comprehensive Cancer Center, Ohio State University, Columbus, OH 43210, USA
}

Background: Although meningioma is a benign tumour, it may cause significant morbidity. Obesity and diabetes are positively associated with meningioma. To evaluate the potential effects of obesity-related prediagnostic glucose, triglycerides and cholesterol on meningioma and of prediagnostic meningioma on these biomarkers, we conducted a cohort study.

Methods: We identified 41355 individuals in the Apolipoprotein MOrtality RISk cohort with values for these biomarkers within 15 years before meningioma diagnosis, death, migration or the end of follow-up. We then estimated hazard ratios (HRs) and their interactions with time and age using Cox regression.

Results: Meningioma was diagnosed in 181 women and 115 men whose median follow-up time was 7 years. Fasting serum glucose level was inversely related to meningioma among women $\left(P_{\text {trend }}=0.0006\right)$ but not men $\left(P_{\text {trend }}=0.24\right)$. Prediagnostic diabetes was inversely related to meningioma in both sexes combined ( $\mathrm{HR}=0.45,95 \%$ confidence interval (Cl) $0.29-0.71)$, as was serum cholesterol within the year before diagnosis $(H R=0.50,95 \% \mathrm{Cl} 0.34-0.72)$.

Conclusions: Paradoxically, hyperglycaemia is inversely associated with meningioma in women. This finding does not necessarily negate the positive role of obesity or diabetes in meningioma development; rather, it may indicate that their effects depend on the stage of development. Furthermore, the prediagnostic tumour may reduce serum cholesterol levels.

Meningioma, a primary tumour arising from the membrane surrounding the brain and spinal cord, accounts for more than one-third of all primary brain and central nervous system tumours (Dolecek et al, 2015). Its annual incidence in the United States is 7.18 per 100000 for benign meningioma and 0.44 per 100000 for borderline and malignant meningioma. Overall, this usually slow-growing tumour is approximately twice as common in women as in men. Although designated a benign tumour, as van Alkemade et al (2012) note, meningioma results in elevated mortality rates and significant morbidity. They also report that most meningioma patients have long-term neurological impairment.

The established meningioma risk factors (Wiemels et al, 2010) include female gender, exposure to ionising radiation (Sadetzki et al, 2005; Claus et al, 2012), exogenous oestrogen use (Benson et al, 2015), familial cancer predisposition syndromes (e.g., neurofibromatosis) (Claus et al, 2011), and possibly presence of autoimmune disease (Hemminki et al, 2013). There is conflicting evidence, reviewed by Turner et al (2013), of protection afforded by allergy. However, there is strong evidence for a role of obesity in

*Correspondence: Dr J Schwartzbaum; E-mail: ja.schwartzbaum@gmail.com

${ }^{6}$ These authors contributed equally to this work.

Received 14 December 2015; revised 17 April 2016; accepted 21 April 2016; published online 2 June 2016

(c) 2016 Cancer Research UK. All rights reserved 0007 - 0920/16 
increasing meningioma risk (Michaud et al, 2011; Rajaraman, 2011; Wiedmann et al, 2013; Shao et al, 2014; Niedermaier et al, 2015; Sergentanis et al, 2015).

Consistent with the well-known association between obesity and diabetes (Eckel et al, 2011), Schwartzbaum et al (2005) found an increased risk of meningioma among men with discharge diagnoses of diabetes as long as 6-7 years before meningioma diagnosis. This finding is supported by the observation in Edlinger et al (2012) of a positive association between prediagnostic serum glucose levels and meningioma. This benign tumour shares several risk factors with malignant tumours, including obesity (Reeves et al, 2007). Therefore, the extensive literature, reviewed by Bosco et al (2015), on the association between the metabolic correlates of obesity (Hollister et al, 1967), including elevated blood glucose, triglyceride and cholesterol levels, and cancer risk, at many sites may be applicable to meningioma. One purpose of the present study was to examine the potential association between glucose, triglyceride and cholesterol levels, and meningioma development.

Reverse causality, the prediagnostic effect of a disease on a proposed risk factor, is perceived as a potential source of bias when the purpose of a study is to detect disease risk factors. However, the value of describing, rather than eliminating, this phenomenon is that it may lead to discovery of indicators of tumour development and consequently to earlier tumour diagnosis. In addition, evaluating reverse causality may provide a better understanding of tumour progression. To discriminate between serum biomarkers that affect meningioma and those affected by the prediagnostic tumour, we examined possible modifying effects of time before diagnosis on the association between the three serum biomarkers and meningioma.

We based our analyses on cohort data from the Swedish Apolipoprotein MOrtality RISk (AMORIS) data set that included results of laboratory tests of fasting serum glucose, triglyceride and total cholesterol levels linked to Swedish national disease and death registries. In addition, we conducted separate analyses of AMORIS serum biomarker data collected from non-fasting participants. Our rationale for including these data is that although non-fasting data may contain more statistical noise (attributable to participants' pretest diets) than the fasting data, they may still produce a signal. In this sense non-fasting results may serve to validate our fasting findings. We therefore include a non-fasting dose-response table in the Supplementary Material.

\section{MATERIALS AND METHODS}

The sample. Our study was derived from the AMORIS cohort, which has been described in detail elsewhere (Walldius et al, 1992, 2001). This Swedish cohort is based on linkage of the Central Automation Laboratory (CALAB, Stockholm, Sweden) database (1985-1996) to that of the National Cancer Registry, the National Patient Register, the Cause of Death Register and the National Register of Emigration (1985-2012). Observation time was defined as the difference between the date of the last glucose, triglyceride and cholesterol test and the date of meningioma diagnosis, death, emigration from Sweden or the end of follow-up (30 December 2012). Information on prediagnostic diabetes was obtained from the National Diabetes Register (Gudbjornsdottir et al, 2003) established in 1996 and the National Patient Registry, which began including outpatient diagnoses in 2001. Both sources of information were established after initiation of the biomarker data collection period (1985), so records on diabetes were not complete; however, presumably they were equally incomplete among cases and non-cases. In addition, to address this issue, we also defined diabetics as individuals in our sample with a fasting glucose level $>6.99 \mathrm{mmoll}^{-1}$. All cohort participants were healthy and referred for clinical laboratory testing as part of routine health screening or were outpatients referred for laboratory testing. None were hospital inpatients at the time of their laboratory tests.

The AMORIS population consists of 812073 participants of all ages with varying information on a number of biomedical factors. The number of these participants with serum glucose, triglyceride and cholesterol readings was 545401 . We next removed participants from the sample whose biomarker values were measured more than 15 years before the date of the last observation, leaving 79797 individuals in the sample. This restriction produced a sample that would allow investigation of both meningioma development and reverse causality, being relatively close to the time of the last observation. Further limitation of the sample to participants who were at least 18 years old at the time of the last observation (i.e., to limit the study to people who were adults at the time of meningioma diagnosis) and who had no missing values for any of the variables that were to be included in the Cox regression analysis (e.g., time of follow-up, age at and date of laboratory test and biomarker values, see Statistical Methods below) reduced the sample to 78389 study participants. Our rationale for the latter restriction was to align the demographic description of the population with the subset that would be included in the multivariable analyses, which are automatically restricted to observations with non-missing values. We next excluded nervous system tumours on the grounds that treatment for these tumours may increase meningioma rates, causing them to differ from other non-cases. Thus, 710 glioma cases (defined by pathology-anatomy diagnosis (PAD) codes (WHO/HS/CANC/24.1) 471, 475, and 476) and 15 ependymoma cases (PAD codes 481, 485, and 486) were excluded. This restriction reduced the sample to 77664 participants, 528 of whom were diagnosed with meningioma (PAD codes 461 and 446). As noted in the Introduction, we analysed data from individuals who were fasting at the time of blood collection $(n=41355)$ and those who were not $(n=36309$; see Supplementary Material) separately. The Ethics Review Board of the Karolinska Institutet (Stockholm, Sweden) approved the study and it complied with the Declaration of Helsinki.

Statistical methods. We used the Cox proportional hazards regression model to estimate serum biomarker dose-response trends. Effect estimates produced by these models are referred to as hazard ratios (HR) and in our study represent the ratio of hazard rates at different biomarker levels. Hazard rates may be roughly interpreted as incidence rates (Hernan, 2010) although they are conditioned on survival to the time of the event (i.e., meningioma). Hazard ratios differ from relative risks, which are ratios of probabilities; however, when referring to previous literature, for convenience, we use the terms risk or risk factor to include results of studies based on both relative risks and HRs.

Follow-up time in our Cox regression models was defined as the time between the age at the last laboratory test and the age at censoring. We first tested linear dose-response trends using polynomial linear contrasts. Next, we modelled time and age interactions and identified a time to last observation-cholesterol interaction and an age at last observation-cholesterol interaction, and thus used separate baseline hazards for categories of time and age at the last observation in our dose-response models. However, stratified dose-response models' HRs were substantially the same (not shown) as those not stratified. We therefore did not stratify our final biomarker dose-response models on age or time. However, we estimated time-biomarker interactions in separate Cox regression models to determine whether there was evidence of reverse causality. We also evaluated separate age-biomarker interactions to examine evidence for competing risks from all causes of death.

To further identify evidence for competing risks, we used a subdistribution hazards model (SAS, version 9.4). Counterfactual 
risk sets in these models include both living study participants at risk of meningioma and those who were at risk when they died. Although the latter group is included in subdistribution hazard risk sets, it is weighted by a value that diminishes with time from their death (Fine and Gray, 1999). While subdistribution hazard models are used to estimate the effects of competing risks, they provide limited information. They evaluate the effect of eliminating death as a terminal event but they do not provide estimates of the proportion of the 'undead' who would have been diagnosed with meningioma had they remained alive.

To verify that our findings were not attributable to the diseases for which the serum biomarkers were measured, we conducted a subsample analysis of study participants whose biomarkers were measured at least 1 year apart. This sample presumably was restricted to study participants who were healthy but routinely screened.

All analyses were conducted using SAS statistical software, version 9.4 (SAS Institute Inc, Cary, NC, USA) or the R language and environment (R Core Team, 2013).

\section{RESULTS}

Table 1 shows that women constitute approximately $60 \%$ of the meningioma cases, reflecting the higher incidence of meningioma among women than men (Wiemels et al, 2010). Also, as shown in
Table 1, the median age at the time of the blood tests for cases was 53 years (IQR $=45,60$ years), while that for non-cases was 61 years (IQR $=50,72$ years). Overall, there were minor differences in median serum biomarker levels between meningioma cases and non-cases, with the cases having slightly lower values than the noncases.

Hazard ratios in Table 2 represent the ratio of meningioma hazard rates in each biomarker category relative to those in the reference (lowest) category. For example, a HR of 0.44 for women whose last fasting serum glucose level was at least $5.5 \mathrm{mmoll}^{-1}$ indicates that their meningioma hazard rate was $56 \%$ lower than that for women whose serum glucose level was $<4.6 \mathrm{mmoll}^{-1}$. Although glucose HRs for women in the highest two serum glucose dose categories were $<1.00$, those for men in these categories were $>1.00$, suggesting that gender modifies the association between serum glucose levels and meningioma. We therefore did not estimate serum glucose hazard ratios for the total sample. Consistent with these gender differences, there was a statistically significant inverse linear association between serum glucose levels and meningioma HRs among women $\left(P_{\text {trend }}=0.0006\right)$ but not among men $\left(P_{\text {trend }}=0.24\right)$. Note also that the $P_{\text {trend }}$ for fasting serum cholesterol among men is of borderline statistical significance $\left(P_{\text {trend }}=0.06\right)$.

Among non-fasting women, HRs over levels of serum glucose (Supplementary Table 1) were similar to those for fasting women (Table 2); however, among non-fasting men HRs were $<1.00$ and

Table 1. Characteristics of fasting study participants and their serum biomarker values by gender

\begin{tabular}{|c|c|c|c|c|c|c|}
\hline & \multicolumn{2}{|c|}{ Women } & \multicolumn{2}{|c|}{ Men } & \multicolumn{2}{|c|}{ Total } \\
\hline & Meningioma & $\begin{array}{c}\text { No } \\
\text { meningioma }\end{array}$ & Meningioma & $\begin{array}{c}\text { No } \\
\text { meningioma }\end{array}$ & Meningioma & $\begin{array}{c}\text { No } \\
\text { meningioma }\end{array}$ \\
\hline \multicolumn{7}{|l|}{ Descriptive variables } \\
\hline Number & 181 & 17544 & 115 & 23515 & 296 & 41059 \\
\hline Median age at laboratory test $\left(I Q R^{a}\right)$, years & $53(45-60)$ & $64(52-76)$ & $54(46-60)$ & $60(50-67)$ & $53(45-60)$ & $61(50-72)$ \\
\hline Median age at last observation (IQR), years & $60(53-68)$ & $73(60-84)$ & $61(54-69)$ & $67(57-76)$ & $61(53-68)$ & $69(58-79)$ \\
\hline $\begin{array}{l}\text { Median time from laboratory test to last } \\
\text { observation (IQR), years }\end{array}$ & $7(3-11)$ & $8(4-12)$ & $7(3-11)$ & $8(4-12)$ & $7(3-11)$ & $8(4-12)$ \\
\hline Median year of laboratory test (IQR) & $1991(1988-1994)$ & $1990(1988-1993)$ & $1990(1988-1994)$ & 1990 (1987-1993) & $1991(1988-1994)$ & 1990 (1988-1993) \\
\hline \multicolumn{7}{|l|}{ Serum biomarkers } \\
\hline Median glucose, $\mathrm{mmoll}^{-1}$ (IQR) & $4.8(4.40-5.10)$ & $5.0(4.50-5.50)$ & $5.2(4.70-5.70)$ & $5.1(4.70-5.70)$ & $4.9(4.55-5.30)$ & $5.1(4.60-5.60)$ \\
\hline Median triglyceride, $\mathrm{mmolI}^{-1}$ (IQR) & $1.0(0.70-1.40)$ & $1.1(0.80-1.60)$ & $1.4(1.00-1.90)$ & $1.3(0.90-1.90)$ & $1.1(0.80-1.50)$ & $1.2(0.80-1.80)$ \\
\hline Median cholesterol, mmoll-1 (IQR) & $5.8(5.10-6.40)$ & $6.0(5.20-6.80)$ & $5.6(5.00-6.40)$ & $5.8(5.00-6.50)$ & $5.7(5.10-6.40)$ & $5.9(5.10-6.70)$ \\
\hline
\end{tabular}

\section{Table 2. Associations between prediagnostic fasting serum biomarkers and meningioma by quartile and gender}

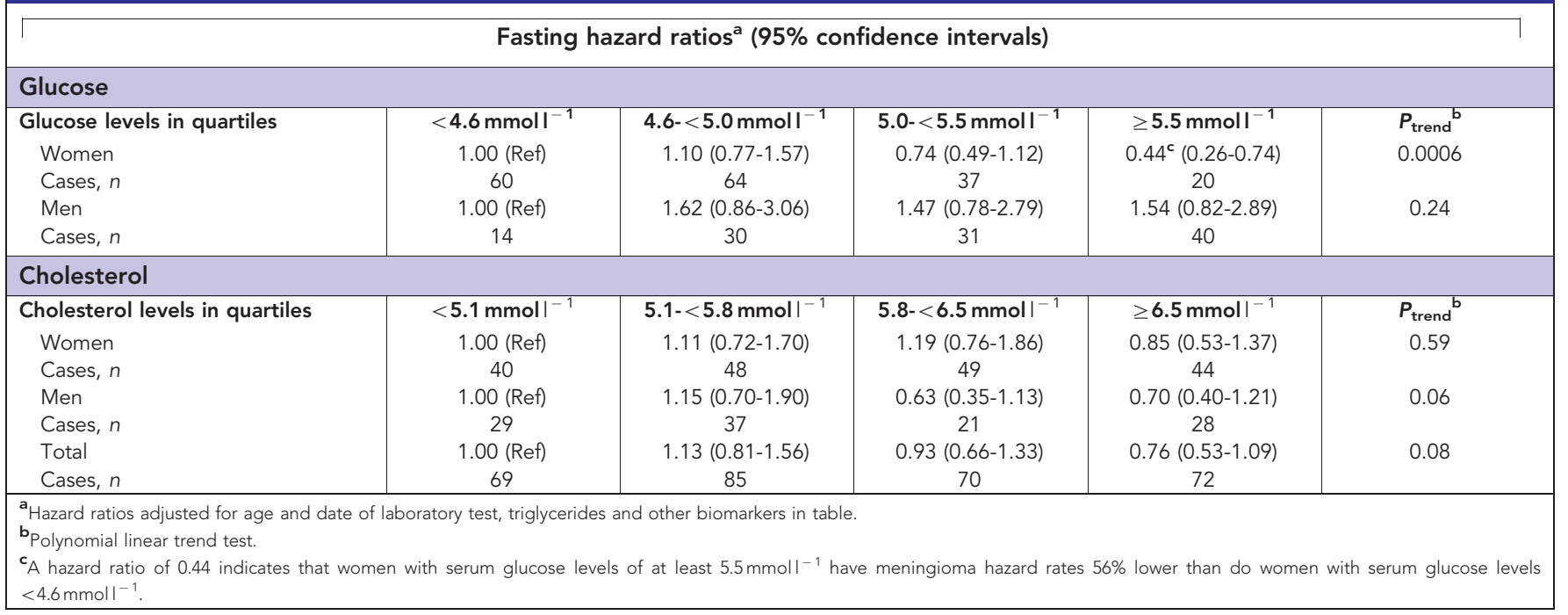



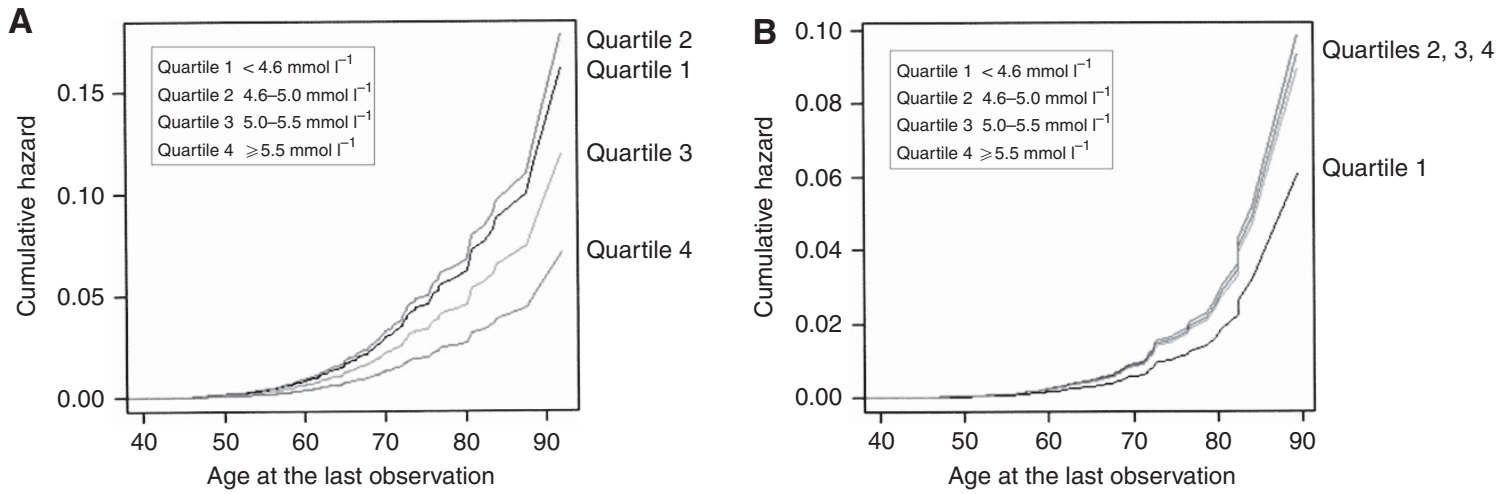

Figure 1. (A) Cumulative hazards of meningioma by quartiles of serum glucose for fasting women. (B) Cumulative hazards of meningioma by quartiles of serum glucose for fasting men.

therefore similar to those observed for fasting and non-fasting women. In addition, among non-fasting men there is no linear trend over levels of cholesterol. Triglyceride levels were not associated with meningioma among both fasting and non-fasting participants (not shown).

Cumulative hazards of meningioma between ages 40 and 90 years at the last observation by quartiles of serum glucose, are shown in Figure $1 \mathrm{~A}$ and $\mathrm{B}$. These graphs extend the findings in Table 2 by illustrating the relative order of serum glucose quartiles over age at the last observation. In fasting women (Figure 1A), the meningioma cumulative hazard rate is highest for women in the lowest two serum glucose quartiles and lowest for women in the highest quartile. In contrast, in fasting men (Figure 1B), the lowest cumulative hazard rate is found in the lowest serum glucose quartile.

We identified only 10 people diagnosed with diabetes who were also subsequently diagnosed with meningioma and 2912 people diagnosed with diabetes who were not. As would be predicted from our analyses of hyperglycaemia, diabetes and meningioma were inversely related $(\mathrm{HR}=0.46,95 \% \mathrm{CI} 0.24-0.87)$. The small number of diabetes diagnoses among the meningioma cases did not allow estimation of sex-specific hazard ratios.

Table 3 shows HRs by time between serum glucose and cholesterol measurement and time at the last observation These HRs differ from those in Table 2 in that they are based on continuous rather than categorical biomarker values. These continuous variables represent the standardised logs $($ mean $=0$, standard deviation $=1$ ) of the original biomarker values. One unit of these standardised logs equals one standard deviation. Thus, HRs in this table indicate changes of meningioma hazard rates with a unit change of the transformed biomarker values. For example, among men within the year before the last observation a one standard deviation increase in the transformed cholesterol value corresponds to a $60 \%$ decrease in the meningioma hazard rate $(\mathrm{HR}=0.40,95 \% \mathrm{CI} 0.26-0.62)$. In addition, among women whose serum glucose was measured 10-15 years before the last observation there is a statistically significant inverse association between serum glucose and meningioma $(\mathrm{HR}=0.34,95 \% \mathrm{CI} 0.22$ 0.54). Among women older than age 69 years at the last observation (Supplementary Table 2), there is a similar inverse association between serum cholesterol level and meningioma ( $\mathrm{HR}=0.67,95 \%$ CI 0.47-0.96).

Subdistribution HRs (Supplementary Table 3) among men and women for serum glucose and cholesterol are similar to those in Table 2. This result may indicate that fasting serum biomarker patterns are not attributable to competing risks of death from all causes. Subdistribution HRs for non-fasting men and women (not shown) are also similar to those in Supplementary Table 1.

The results of the analyses of the fasting subgroup whose biomarker values were measured at least 1 year apart (suggesting that these tests were components of routine screening examinations) are shown in Supplementary Table 4. Again, the trend over quartiles of serum glucose is similar to that in Table 2, indicating that our findings may not be exclusively attributable to the underlying diseases for which biomarker tests may have been conducted. Non-fasting HRs for this subgroup (not shown) are also similar to those in Supplementary Table 1.

\section{DISCUSSION}

Previous literature indicates that obesity increases meningioma risk (Michaud et al, 2011; Rajaraman, 2011; Wiedmann et al, 2013; Shao et al, 2014; Niedermaier et al, 2015; Sergentanis et al, 2015); obesity also increases risk of type 2 diabetes (Eckel et al, 2011); we therefore expected hyperglycaemia to be positively associated with meningioma. Instead, within 15 years before the last observation we found inverse associations between prediagnostic glucose levels and meningioma among both fasting women and non-fasting women and men. Consistent with these results, we observed inverse relationships between prediagnostic diabetes and meningioma. We also found that serum cholesterol levels, measured within the year before the last observation were inversely related to meningioma hazard rates.

Ours is the first study to identify an inverse association between prediagnostic serum glucose levels and meningioma. Although there is evidence of similar inverse associations between prediagnostic serum glucose or diabetes and glioma (Schwartzbaum et al, 2005; Edlinger et al, 2012) and prostate cancer (Van Hemelrijck et al, 2011; Haggstrom et al, 2014), associations between prediagnostic serum glucose and cholesterol levels and cancer incidence are generally positive (Bosco et al, 2015; Stocks et al, 2015).

Gender differences in tumour risk are sometimes attributable to the effects of exogenous and endogenous sex hormones. Elevated endogenous oestrogen levels, which are associated with obesity in postmenopausal women (Cleary and Grossmann, 2009), also increase meningioma risk (Niedermaier et al, 2015). Benson et al (2015) present credible evidence of an increased risk of meningioma among women who use oestrogen-only hormone replacement therapy. In addition, endogenous sex hormones participate in the regulation of glucose homeostasis (Picard et al, 2002; Kim and Halter, 2014; Lopez and Tena-Sempere, 2015). However, in a study of tissue samples from 510 tumours Korhonen et al (2006) found progesterone receptors in $87.1 \%$ of the samples from women and $91.5 \%$ of those from men. They also observed an approximately equal distribution of oestrogen and androgen receptors in these tumours between the sexes. They therefore conclude that sex hormone receptors per se are not the source of 
meningioma gender differences. However, the role of these receptors may differ in men and women. For example, Picard et al (2002) show that a progesterone receptor antagonist reduces fasting glycaemia levels in female but not in male mice. Assuming these findings pertain to humans, they indicate the complexity of the relationship between sex hormones and serum glucose levels. Furthermore, there are two types of progesterone receptors; one may inhibit meningioma cell proliferation (Tonn et al, 1997), the other may promote it (Inoue et al, 2002). Increasing the probability that progesterone affects meningioma development is the fact that it can be synthesised in the nervous system, where it modulates neuronal excitability (Reddy, 2010). An understanding of the role of sex hormones in meningioma aetiology and progression may provide additional insights into treatment strategies.

The inverse association between cholesterol and meningioma within the year before the last observation is consistent with the tumour's increased need for low-density lipoprotein (Rudling et al, 1990), but this association is not unique to meningioma. Rather it has been observed in individuals diagnosed with malignant tumours at several sites (Peterson et al, 1985; Kritchevsky and Kritchevsky, 1992). In contrast, Edlinger et al (2012) found no association between total cholesterol levels and meningioma, although they did not evaluate their data by time or age before the last observation.

A limitation of the present study is that we did not have a sufficient number of participants with information on variables that may confound the serum glucose-meningioma association. These potentially confounding variables include low- and highdensity lipoprotein, blood pressure, body mass index, and endogenous and exogenous sex hormone levels. Their absence not only limits our ability to adjust for confounding bias, but also restricts our choice of models to identify competing risks (Moodie et al, 2014).

Although the subdistribution hazard model provided no evidence of competing risks, there was a relatively strong inverse association between glucose and meningioma among women whose glucose was measured 10-15 years before diagnosis, death or censoring (Table 3). This finding may result from deaths of these women from tumours at other sites or cardiovascular disease. However, there is no evidence of a modifying effect of age at diagnosis on the inverse glucose-meningioma association among fasting women (Supplementary Table 2), while among women over 69 years old at the time of last observation there is an inverse cholesterol-meningioma association, which is also consistent with the presence of competing risks.
There are several plausible biological mechanisms that may account for our findings. First, there is an extensive body of literature suggesting that Metformin, a drug used to treat diabetes, reduces cancer risk (Bosco et al, 2015). However, a recent study of the effects of Metformin on meningioma cell culture failed to find an effect (Wilisch-Neumann et al, 2014). Second, angiogenesis is an important component of meningioma growth (Preusser et al, 2012). Diabetes and hyperglycaemia may offer protection against meningioma growth by inhibiting cerebral blood flow (Chung et al, 2015; Rusinek et al, 2015), thus making it more difficult for the tumour to establish a blood supply. Third, diabetic female rats have lower levels of serum progesterone (Pournaghi et al, 2012), and diabetic mice (Barbosa-Desongles et al, 2013) and humans (Kim and Halter, 2014) have lower levels of androgens (BarbosaDesongles et al, 2013; Kim and Halter, 2014) than do non-diabetic representatives of these species. To the extent that these hormones are involved in tumour development, their reduction may confer protection against the tumour. Fourth, the inverse association between serum glucose and meningioma may be attributable to the effects of the preclinical tumour on serum glucose levels. Like other tumours, meningioma requires large amounts of glucose for construction of cell walls and other components of cell proliferation. This phenomenon is referred to as the Warburg effect, and there is evidence of its presence during meningioma progression (Bharadwaj et al, 2015). Thus, women with lower serum glucose levels may have preclinical tumours that are usurping their circulating glucose. However, if reverse causality accounted for our findings, we would expect the inverse serum glucose-meningioma association to become stronger closer to the time of diagnosis. It does not. Rather, the association appears to be strongest 10-15 years before diagnosis.

Our findings do not necessarily negate the roles of known meningioma risk factors (Wiemels et al, 2010). For example, while obesity may increase meningioma risk (Niedermaier et al, 2015), through an as yet unknown mechanism, it may also increase hyperglycaemia risk (Eckel et al, 2011), thereby inhibiting tumour growth. We therefore speculate that obesity and hyperglycaemia affect different stages of meningioma development.

Assuming that our findings can be confirmed, they provide evidence for the effects of the physiological environment on meningioma. In addition, the lowering of serum cholesterol for no apparent reason may be a biomarker of meningioma development, although this sign is not unique to meningioma (Peterson et al, 1985; Kritchevsky and Kritchevsky, 1992). In attempting to replicate our findings, it would be worthwhile

Table 3. Adjusted meningioma fasting hazard ratios $^{\text {a }}$ for serum biomarkers by time before diagnosis, death or censoring

\begin{tabular}{|c|c|c|c|c|}
\hline \multicolumn{5}{|c|}{ Fasting hazard ratios ( $95 \%$ confidence intervals) } \\
\hline \multicolumn{5}{|l|}{ Glucose $^{b}$} \\
\hline Men & $1.06(0.57-1.98)$ & $1.09(0.75-1.57)$ & $1.14(0.84-1.55)$ & $0.82(0.53-1.29)$ \\
\hline Total & $0.76(0.43-1.35)$ & $0.90(0.67-1.20)$ & $1.05(0.84-1.31)$ & $0.61(0.50-0.75)$ \\
\hline \multicolumn{5}{|l|}{ Cholesterol $^{\mathrm{b}}$} \\
\hline Total & $0.50(0.34-0.72)$ & $0.91(0.71-1.17)$ & $0.95(0.77-1.18)$ & $0.95(0.74-1.22)$ \\
\hline \multicolumn{5}{|l|}{ Number of cases } \\
\hline Women & 24 & 47 & 46 & 64 \\
\hline Men & 16 & 24 & 38 & 37 \\
\hline Total & 40 & 71 & 84 & 101 \\
\hline
\end{tabular}


to simultaneously evaluate prediagnostic obesity and levels of endogenous progesterone, androgens and oestrogen to examine whether and how they affect meningioma development and growth.

\section{ACKNOWLEDGEMENTS}

This research was funded by the National Cancer Institute, National Institutes of Health (grant number R01CA122163) to Judith Schwartzbaum.

\section{CONFLICT OF INTEREST}

The authors declare no conflict of interest.

\section{REFERENCES}

Barbosa-Desongles A, Hernandez C, De Torres I, Munell F, Poupon MF, Simo R, Selva DM (2013) Diabetes protects from prostate cancer by downregulating androgen receptor: new insights from LNCaP cells and PAC120 mouse model. PLoS ONE 8(9): e74179.

Benson VS, Kirichek O, Beral V, Green J (2015) Menopausal hormone therapy and central nervous system tumor risk: large UK prospective study and meta-analysis. Int J Cancer 136(10): 2369-2377.

Bharadwaj S, Venkatraghavan L, Mariappan R, Ebinu J, Meng Y, Khan O, Tung T, Reyhani S, Bernstein M, Zadeh G (2015) Serum lactate as a potential biomarker of non-glial brain tumors. J Clin Neurosci 22(10): $1625-1627$.

Bosco C, Wulaningsih W, Melvin J, Santaolalla A, De Piano M, Arthur R, Van Hemelrijck M (2015) Metabolic serum biomarkers for the prediction of cancer: a follow-up of the studies conducted in the Swedish AMORIS study. Ecancermedicalscience 9: 555.

Chung CC, Pimentel D, Jor'dan AJ, Hao Y, Milberg W, Novak V (2015) Inflammation-associated declines in cerebral vasoreactivity and cognition in type 2 diabetes. Neurology 85(5): 450-458.

Claus EB, Calvocoressi L, Bondy ML, Schildkraut JM, Wiemels JL, Wrensch M (2011) Family and personal medical history and risk of meningioma. J Neurosurg 115(6): 1072-1077.

Claus EB, Calvocoressi L, Bondy ML, Schildkraut JM, Wiemels JL, Wrensch M (2012) Dental x-rays and risk of meningioma. Cancer 118(18): 4530-4537.

Cleary MP, Grossmann ME (2009) Minireview: Obesity and breast cancer: the estrogen connection. Endocrinology 150(6): 2537-2542.

Dolecek TA, Dressler EV, Thakkar JP, Liu M, Al-Qaisi A, Villano JL (2015) Epidemiology of meningiomas post-Public Law 107-206: The Benign Brain Tumor Cancer Registries Amendment Act. Cancer 121(14): 24002410.

Eckel RH, Kahn SE, Ferrannini E, Goldfine AB, Nathan DM, Schwartz MW, Smith RJ, Smith SR (2011) Obesity and type 2 diabetes: what can be unified and what needs to be individualized? J Clin Endocrinol Metab 96(6): 1654-1663.

Edlinger M, Strohmaier S, Jonsson H, Bjorge T, Manjer J, Borena WT, Haggstrom C, Engeland A, Tretli S, Concin H, Nagel G, Selmer R, Johansen D, Stocks T, Hallmans G, Stattin P, Ulmer H (2012) Blood pressure and other metabolic syndrome factors and risk of brain tumour in the large population-based Me-Can cohort study. J Hypertens 30(2): 290-296.

Fine JP, Gray RJ (1999) A proportional hazards model for the subdistribution of a competing risk. J Am Stat Assoc 94: 496-509.

Gudbjornsdottir S, Cederholm J, Nilsson PM, Eliasson B (2003) The National Diabetes Register in Sweden: an implementation of the St. Vincent Declaration for Quality Improvement in Diabetes Care. Diabetes Care 26(4): $1270-1276$

Haggstrom C, Stocks T, Nagel G, Manjer J, Bjorge T, Hallmans G, Engeland A, Ulmer H, Lindkvist B, Selmer R, Concin H, Tretli S, Jonsson H, Stattin P (2014) Prostate cancer, prostate cancer death, and death from other causes, among men with metabolic aberrations. Epidemiology 25(6): 823-828.
Hemminki K, Liu X, Forsti A, Ji J, Sundquist J, Sundquist K (2013) Subsequent brain tumors in patients with autoimmune disease. Neuro Oncol 15(9): $1142-1150$

Hernan MA (2010) The hazards of hazard ratios. Epidemiology 21(1): 13-15. Hollister LE, Overall JE, Snow HL (1967) Relationship of obesity to serum triglyceride, cholesterol, and uric acid, and to plasma-glucose levels. Am J Clin Nutr 20(7): 777-782.

Inoue T, Akahira J, Suzuki T, Darnel AD, Kaneko C, Takahashi K, Hatori M, Shirane R, Kumabe T, Kurokawa Y, Satomi S, Sasano H (2002) Progesterone production and actions in the human central nervous system and neurogenic tumors. J Clin Endocrinol Metab 87(11): 5325-5331.

Kim C, Halter JB (2014) Endogenous sex hormones, metabolic syndrome, and diabetes in men and women. Curr Cardiol Rep 16(4): 467.

Korhonen K, Salminen T, Raitanen J, Auvinen A, Isola J, Haapasalo H (2006) Female predominance in meningiomas can not be explained by differences in progesterone, estrogen, or androgen receptor expression. J Neurooncol 80(1): 1-7.

Kritchevsky SB, Kritchevsky D (1992) Serum cholesterol and cancer risk: an epidemiologic perspective. Annu Rev Nutr 12: 391-416.

Lopez M, Tena-Sempere M (2015) Estrogens and the control of energy homeostasis: a brain perspective. Trends Endocrinol Metab 26(8): 411-421.

Michaud DS, Bove G, Gallo V, Schlehofer B, Tjonneland A, Olsen A, Overvad K, Dahm CC, Teucher B, Boeing H, Steffen A, Trichopoulou A, Bamia C, Kyrozis A, Sacerdote C, Agnoli C, Palli D, Tumino R, Mattiello A, Bueno-de-Mesquita HB, Peeters PH, May AM, Barricarte A, Chirlaque MD, Dorronsoro M, Jose Sanchez M, Rodriguez L, Duell EJ, Hallmans G, Melin BS, Manjer J, Borgquist S, Khaw KT, Wareham N, Allen NE, Travis RC, Romieu I, Vineis P, Riboli E (2011) Anthropometric measures, physical activity, and risk of glioma and meningioma in a large prospective cohort study. Cancer Prev Res 4(9): 1385-1392.

Moodie EE, Stephens DA, Klein MB (2014) A marginal structural model for multiple-outcome survival data:assessing the impact of injection drug use on several causes of death in the Canadian Co-infection Cohort. Stat Med 33(8): 1409-1425.

Niedermaier T, Behrens G, Schmid D, Schlecht I, Fischer B, Leitzmann MF (2015) Body mass index, physical activity, and risk of adult meningioma and glioma: a meta-analysis. Neurology 85: 1342-1350.

Peterson C, Vitols S, Rudling M, Blomgren H, Edsmyr F, Skoog L (1985) Hypocholesterolemia in cancer patients may be caused by elevated LDL receptor activities in malignant cells. Med Oncol Tumor Pharmacother 2: 143-147.

Picard F, Wanatabe M, Schoonjans K, Lydon J, O’Malley BW, Auwerx J (2002) Progesterone receptor knockout mice have an improved glucose homeostasis secondary to beta-cell proliferation. Proc Natl Acad Sci USA 99(24): 15644-15648.

Pournaghi P, Sadrkhanlou RA, Hasanzadeh S, Foroughi A (2012) An investigation on body weights, blood glucose levels and pituitary-gonadal axis hormones in diabetic and metformin-treated diabetic female rats. Vet Res Forum 3(2): 79-84.

Preusser M, Hassler M, Birner P, Rudas M, Acker T, Plate KH, Widhalm G, Knosp E, Breitschopf H, Berger J, Marosi C (2012) Microvascularization and expression of VEGF and its receptors in recurring meningiomas: pathobiological data in favor of anti-angiogenic therapy approaches. Clin Neuropathol 31(5): 352-360.

R Core Team (2013) R: A Language and Environment for Statistical Computing. R Foundation for Statistical Computing:: Vienna, Austria.

Rajaraman P (2011) Hunting for the causes of meningioma-obesity is a suspect. Cancer Prev Res (Phila) 4(9): 1353-1355.

Reddy DS (2010) Neurosteroids: endogenous role in the human brain and therapeutic potentials. Progr Brain Res 186: 113-137.

Reeves GK, Pirie K, Beral V, Green J, Spencer E, Bull D (2007) Cancer incidence and mortality in relation to body mass index in the Million Women Study: cohort study. BMJ 335(7630): 1134.

Rudling MJ, Angelin B, Peterson CO, Collins VP (1990) Low density lipoprotein receptor activity in human intracranial tumors and its relation to the cholesterol requirement. Cancer Res 50(3): 483-487.

Rusinek H, Ha J, Yau PL, Storey P, Tirsi A, Tsui WH, Frosch O, Azova S, Convit A (2015) Cerebral perfusion in insulin resistance and type 2 diabetes. J Cerebral Blood Flow Metab 35(1): 95-102.

Sadetzki S, Flint-Richter P, Starinsky S, Novikov I, Lerman Y, Goldman B, Friedman E (2005) Genotyping of patients with sporadic and radiation- 
associated meningiomas. Cancer Epidemiol Biomarkers Prev 14(4): 969-976.

Schwartzbaum J, Jonsson F, Ahlbom A, Preston-Martin S, Malmer B, Lonn S, Soderberg K, Feychting M (2005) Prior hospitalization for epilepsy, diabetes, and stroke and subsequent glioma and meningioma risk. Cancer Epidemiol Biomarkers Prev 14(3): 643-650.

Sergentanis TN, Tsivgoulis G, Perlepe C, Ntanasis-Stathopoulos I, Tzanninis IG, Sergentanis IN, Psaltopoulou T (2015) Obesity and risk for brain/CNS tumors, gliomas and meningiomas: a meta-analysis. PLOS ONE 10(9): e0136974.

Shao C, Bai LP, Qi ZY, Hui GZ, Wang Z (2014) Overweight, obesity and meningioma risk: a meta-analysis. PLoS ONE 9(2): e90167.

Stocks T, Bjorge T, Ulmer H, Manjer J, Haggstrom C, Nagel G, Engeland A, Johansen D, Hallmans G, Selmer R, Concin H, Tretli S, Jonsson H, Stattin P (2015) Metabolic risk score and cancer risk: pooled analysis of seven cohorts. Int J Epidemiol 44(4): 1353-1363.

Tonn JC, Ott MM, Bouterfa H, Kerkau S, Kapp M, Muller-Hermelink HK, Roosen K (1997) Inverse correlation of cell proliferation and expression of progesterone receptors in tumor spheroids and monolayer cultures of human meningiomas. Neurosurgery 41(5): 1152-1159.

Turner MC, Krewski D, Armstrong BK, Chetrit A, Giles GG, Hours M, McBride ML, Parent ME, Sadetzki S, Siemiatycki J, Woodward A, Cardis E (2013) Allergy and brain tumors in the INTERPHONE study: pooled results from Australia, Canada, France, Israel, and New Zealand. Cancer Causes Control 24(5): 949-960.

van Alkemade H, de Leau M, Dieleman EM, Kardaun JW, van Os R, Vandertop WP, van Furth WR, Stalpers LJ (2012) Impaired survival and long-term neurological problems in benign meningioma. Neuro Oncol 14(5): 658-666.
Van Hemelrijck M, Garmo H, Holmberg L, Walldius G, Jungner I, Hammar N, Lambe M (2011) Prostate cancer risk in the Swedish AMORIS study: the interplay among triglycerides, total cholesterol, and glucose. Cancer 117(10): 2086-2095.

Walldius G, Jungner I, Holme I, Aastveit AH, Kolar W, Steiner E (2001) High apolipoprotein B, low apolipoprotein A-I, and improvement in the prediction of fatal myocardial infarction (AMORIS study): a prospective study. Lancet 358(9298): 2026-2033.

Walldius G, Jungner I, Kolar W, Holme I, Steiner E (1992) High cholesterol and triglyceride values in Swedish males and females: increased risk of fatal myocardial infarction. First report from the AMORIS (Apolipoprotein related MOrtality RISk) study. Blood Pressure Suppl 4: $35-42$.

Wiedmann M, Brunborg C, Lindemann K, Johannesen TB, Vatten L, Helseth E, Zwart JA (2013) Body mass index and the risk of meningioma, glioma and schwannoma in a large prospective cohort study (The HUNT Study). Br J Cancer 109(1): 289-294.

Wiemels J, Wrensch M, Claus EB (2010) Epidemiology and etiology of meningioma. J Neurooncol 99(3): 307-314.

Wilisch-Neumann A, Pachow D, Wallesch M, Petermann A, Bohmer FD, Kirches E, Mawrin C (2014) Re-evaluation of cytostatic therapies for meningiomas in vitro. J Cancer Res Clin Oncol 140(8): 1343-1352.

This work is published under the standard license to publish agreement. After 12 months the work will become freely available and the license terms will switch to a Creative Commons AttributionNonCommercial-Share Alike 4.0 Unported License.

Supplementary Information accompanies this paper on British Journal of Cancer website (http://www.nature.com/bjc) 